\title{
Global Harmonization through Restoration of Feminine Power
}

\author{
Hillary Claire Snedeker
}

\author{
China International Personnel Training Center, China
}

\begin{abstract}
The future of women is the same as our past and present global state of women as well as human kind. The notion of "this is a man's world" has dictated so much of the Earths energy that it has often seeped down into our inner voices and thoughts destroying our natural balance. A restoration of feminine power is the greatest most pivotal balance act towards the Global Harmonization of the Human Race. She who creates life, gives life, and nurtures life has a great power and understanding to protect life as well as undoubtedly having the right to participate in how the collective life of the human race exists and precedes as well as her own. Female domination is not the goal. Simply, global harmony is the end game. Restoration of feminine power has the potential to heal and liberate our men and women cross culturally and intersectionally in every aspect through which we suffer while simultaneously strengthening the connection of all creatures whom we share the Earth with further alleviating environmental issues. The future of women is the future of the human race and our last option is our only option yet tried- global harmony.
\end{abstract}

Keywords: Global Harmony, Feminine Power, Witch-hunt, Revolution

\section{Introduction}

For centuries Peoples Revolutions have 'struggled for space' and 'fought for rights' in structures that benefit from actively suppressing them. We have heard great speeches throughout time, languages and cultures express the same notion. From the First Peoples and their ancestors in which their land, lives and livelihoods were and are being exploited and eradicated to people and their ancestors marginalized by kidnappings and/or forced migration into foreign lands. Throughout time, languages and cultures we have witnessed powerful revolutions in the form of Civil Rights Movement, Indigenous Rights Movement, Women's Rights Movement, LGBTQ Rights Movement, Workers Rights Movements, Animal and Environmental Rights Movements and the list goes on. Each movement expressing the same sentiment on the natural right of self-determination.

I plan to expose on a surface level some critical instances when separation from our natural existence, self, environment and one another served as control mechanisms for such dominating systems to gain and continue to control. I hope by doing so to inspire a desire for a deeper connection of our natural selves and natural world and strive for a natural global community-to question deeper our lifestyles, the choices we are allotted, the choices we are not, the choices we make and the choices we do not. When we focus on an immediate, new era of Global Harmonization and uniting respectively as a collective human race is when true equality can manifest, and balance be restored.

Bell hooks rightfully labels the current (western) political realm as an imperialistic white supremacy capitalistic patriarchy (hooks, 2014) Such systems have controlled and lead the commerce and design of this world and has marginalized the majority of people on this planet if not annihilated them entirely. It is easy to dismiss such claims as "sins of my father" or as "necessities for the development of the 'modern' world" neglecting selfparticipation and perpetuation by justifying one's lifestyle as superior or as modern. However, the lack of whole-hearted reflection and hearing the true cries of self and humanity creates a (potentially unknowing) active perpetrator and a new generation of propelling the same atrocities keeping the current systems of oppression in 
full gear. We cannot ignore our colonial/imperialistic tragedies, short comings, wrong doings and mistakes. If left unaddressed this capitalist patriarchy will continue the destructive trajectory while pacifying only a few humanitarian cries as a disguise of "progress".

Each ideology in bell hooks suggested political system can be synchronically and diachronically broken down and assessed individually and collectively highlighting several common threads. Arguably one of the deepest and strongest thresholds for such oppressive forces retaining power over the masses is the appropriation, degradation and suppression of feminine power. In order to better combat systems and ideologies opposing global harmony we must restore feminine power.

Although often misunderstood or distorted, In the simplest of terms Webster defines feminism as "the theory of political, economic and social equality of the sexes." Feminism is equality, in favor of both sexes, all gender identifications, all nationalities and all classes. It is named such because the suffering needed to be pinpointed and labeled. Just as racism is called so because the injustice is specifically linked to race-be that as it may exist only as a socially made construct; like gender. Feminism is linked to the suffering of the arbitrarily attributed feminine traits or femininity found in both male and female. We have seen struggles within the feminine movements for lack of inclusion or outright misuse of meaning, projected target and/or motion. As well as having a 'men are the enemy' mindset, focusing on male gains from the current systems neglecting their suppression of self and pain or focusing on one specific class or 'race' of women's needs. However, I believe it is critical to link sexism, racism, classism and poverty under the umbrella of white supremacy imperialistic capitalist patriarch society rampant in the West and intermingled in the world. I would like to focus on the constraints placed upon women due to the disenfranchisement of feminine power being the bottom factor that enables the 'success' of all oppressive ideologies to generate unnecessary suffering to differing races, genders, classes and environments. To gain political, economic and social equity for all we must address the underlining issue of denying our true natural selves- contemplate and explore how unnatural and destructive it is to conform to institutionalized gender roles and the systems they produce and endorse. Feminism is being the most natural and true form of oneself and demanding and harboring a safe space for such discovery and being.

I would like to follow the framework of bell hooks' assertion of the current western political system being a white supremacy imperialistic capitalistic patriarchy (Hooks,2014) which stems from ancient conquests and spread of such ideologies leading to a genderization of populations creating a benefit of power for attributing then devaluing feminine traits and oppressing emotional fluidity while subjugating and abusing women in efforts to control and exploit the population for the controlling class. While the counterparts suffering (men) is not as blatantly apparent, it is still very much in existence and in terms of the core value of feminism, the freedom and ability to be the most natural and true form of oneself, arguably equally detrimental. The existence of these systems and their ideologies have permeated time and cultures and have kept the potential of Global Harmony at bay and humanity off balance. The restoration of feminine power has the potential to destroy the chains imposed by such systems, liberating the masses, easing the burdens placed on our environment and creating a space for Global Harmony.

\section{White Supremacy}

Now, then in order to understand white supremacy we must dismiss the fallacious notion that white people can give anybody their freedom. - Stokely Carmichael (Carmichael, 1966)

To site Webster once more, White supremacy, synonymously euro centrism, is reflecting a tendency to interpret the world in terms of European or Anglo-American values and experiences. (Webster) There has not been a part of this world untouched by the claws of European culture damaging, distorting and disrupting their own culture, or their perception of self and how we see one another. Once the ruling classes in Europe were able to stifle, separate and exploit their own people, the ball kept rolling creating a Eurocentric reach worldwide. Europe has created a dominating global system in which Peoples and/or whole counties either buy in or succumb to. If 
devaluation and control of women is the anchor of the ship, then white supremacy is the North Star of the four major directional pulls steering the current dominating systems home.

Riane Eisler, author of The Chalice and the Blade, finely argues that one of the most damning societal structural shifts, dating back to the Neolithic era, was the transformation from a partnership society to a domineering society. Removing the respect from giving life, to taking it. Studies of Neolithic artwork show "no indications of war or glaring social inequalities". (Sahely, 2017) The once highly regarded Goddess became the wife or concubine of the male deities. Thus creating a significant gender implication of superiority, while the worship of the Earth goddess as a creator and nourisher of life (an undeniable fact and actual power held by almost all women) did not show any creation of dominating roles. Warfare and enslavement began to plague the social construct and "by 1100 BC, Eisler wrote, "it was all over." The dominator model, in the form of a patriarchy, had completely gained control. Women, previously equal to men for at least $\sim 30,000$ years, suddenly began to experience a lesser status. They were marginalized in Ancient Greece, whose democracy "excluded most of the population (giving no participation to women and slaves)."'” (Sahely, 2005) Eventually the shift of worshiping the Earth Goddess to the Sky God was solidified as seen in the Roman Empire with the invention of Christianity which Eisler observed, that "it is God's will that woman be ruled by man." which further propelled the transition of the domineering society and created/manipulated some of the sharpest tools of population control that fostered Euro centrism to manifest- gender roles, religion, race and control of resources i.e. capital.

Although leaving out religion in his critique of white material privilege, Ajuma Baraka says it well in his article The Story of Charlottesville was written in Blood in the Ukraine, That "the structures of white power, that is the structures and institutions that provide the material base for Euro-American white supremacy and its ideological reproduction, should be the focus of radical opposition. But the capitalist order and its institutions - the World Trade Organization, IMF, World Bank, and global Westernized higher education that serves as the material basis for hegemonic white supremacist power - escape critical scrutiny because popular attention is directed against a David Duke and a Donald Trump... [those who find fault in the system] would rather fight against those superficial caricatures of racism than engage in more difficult ideological work involving real selfsacrifice - purging themselves of all racial sentimentality associated with the mythology of the place of white people, white civilization and whiteness in the world in order to pursue a course for justice that will result in the loss of white material privilege.” (Baraka, 2017)

\section{Patriarchy}

"To emancipate woman is to refuse to confine her to the relations she bears to man, not to deny them to her; let her have her independent existence and she will continue none the less to exist to him also; mutually recognizing each other as subject, each will yet remain for the other another." - Simone De Beauvoir

In the article, Is Eurocentrism the Root Problem in our Present World, Bichara Sachley emphasizes the importance of degenderizing the terminology of patriarchy being as the "domineering/partnership dichotomy is neither ideological specific (both capitalism and communism can, and have, operated with dominator values ) or gender specific- both women and men can, and do, embody dominator attitudes." (Sahely, 2017) According to bell hooks "most of us learn patriarchal attitudes in our family of origin and they are usually taught to us by our mothers [and] reinforced by school and religious institutions." She further testifies that the rules of patriarchy are "so deeply embedded in our collective conscious... that female headed households embrace and promote patriarchal thinking with a far greater passion then two parent houses" (hooks,2014) Which begs the questionwhere is the connection with oneself- is it damaged, ignored or lost? The design of patriarchy is so necessary for constructing the web of the domineering system that it is hardly even identifiable to some or addressed properly. In India for example, several significant invaders altered the organization of power and even brought new religions to the lands, but it wasn't until the British imperialistic invasion that the social fabric of the societies 
were altered. "The British, while pursuing commercial aims, intruded the domain of the private life of the Indians." (Shodhganga, 1994) Ashish Nandys' design of Indian societies prior to British colonialization were that of "rather fluid and permeable identities in which ideas about bisexual and androgyny features strongly and in which "softer" forms of creativity and intuition were not identified with femininity nor values of violence and power with masculinity."(Shodhganga, 1994) Meaning over time Britain disturbed the cultural norms and traditions by engendering certain characteristics leading to an engenderment of work which reflected the European misogynistic values and created a space for the infiltration of Eurocentric patriarchy in the cultural, economic, and political realm. During the revolution to gain independence from Britain, women were not allowed to "identify gender or patriarchy as a source of oppression... instead women attacked colonialism" (Shodhganga,1994) helping free their country from their imperialistic oppressors while redirecting their oppression to the Eurocentric patriarchy embedded within the countries new forming independence and culture.

Similarly, in the pre-Columbian societies in America, women held powerful positions "as reflected by the existence of many important female deities in their religion...but with the Spaniards arrival everything changed as they brought their baggage of misogynous beliefs and restructured the economy and political power in ways that favored men. Women suffered also at the hands of the traditional chiefs who in order to maintain their power, began to take over the communal lands and expropriate the female members of the community from land use and water rights." (pp. 230)

Perhaps less obvious than the oppression of women under a patriarchal system and certainly less discussed, is racial oppression. Racism and patriarchy are two interrelated and mutually supporting systems of domination. (Roberts, 1992) Entire economic systems have been supported by slave labor, and as in America for example, liberation of such system only deepened a classist society while reprocessing slavery under the design of capitalistic wage labor all the while remaining a white supremacy playground. Women were being used as tools to perpetuate this domineering society either unbeknownst or obviously and their roles depended on their 'race'. Control of women and their bodies only make sense in a domineering system seeing as women not only create life but have also been tasked with the duty of teaching moral guidance. Essentially "Black women produced to replenish, and white women produced to continue legacy" (Hooks, 2014) Just continuing to add more mazes to redirect inclusivity and further wedge solidarity.

\section{Imperialism}

"I think no one knows what humanitarian intervention means. If I were a person who was non-American, I would think humanitarian intervention is just another name for United States imperialism." -Stanley Hauerwas (Berlatsky, 2013)

The European Imperial crusades were destructive to every aspect of life, from the underground to the intangible up. The transition from the Earth Goddess to the sky god not only shifted societies from a partnership to a domineering one but also divorced the relationship with the natural Earth.

During the medieval times, the controlling class targeted communal spaces, resources and customs in order to derail self-sufficiency and promote a lifestyle dependent on wage and commodities. Silvia Federici theorizes that the prosecutions of the heretics was the build-up leading to the European witch hunts which separated the masses, depleted the power of women, and was in part the blue print for the social control and order that lead way to the imperialistic control that cultivated into the colonies.

The proletariat class participated in fairly gender-neutral work and shared a strong solidarity posing a viable threat to the controlling class. When revolts arose against the controlling classes, woman were at the front lines of organization and implementation. "The clergy recognized the power that sexual desire gave women over men and persistently tried to exorcise it by identifying holiness with avoidance of women and sex" (Federici, 2004 page 37) This planted a seed of separation and created grounds for justification of the prosecution of heretics, 
developing over time into the prosecution of witches. Prior to the witch hunts, the black death had just readjusted the labor force in favor of the proletariat class and the revolutions and revolts were gaining much success. In order to separate the solidarity of the working classes to gain back control the bourgeois, nobility and church slowly began to form an absolute state which worked together to destroy the relationships of the working class by focusing their attack on women. Due to the thirty to forty percent population loss, the work force was in high need of laborers and "women's control over [their] reproduction seemed to pose a threat to economic and social stability." Municipal authorities started criminalizing contraception, abortion, sodomy and infanticide, as well as legalizing prostitution (going as far as tax funded brothels) and "practically [decriminalizing] rape. The gang rape of proletarian women became a common practice" which perpetrators would hardly receive a slap on the wrist, and felt no need to try and conceal their acts. Its projected in some areas of Europe "on average half of the town male youth, at some point, engaged in these assaults." "The legalization of rape created a climate of intense misogyny that degraded all women regardless of class." (Federici, 2004, pp. 40-46)

One major key note on the transition from heretics to witches was the roles women played during the middle ages as midwives and community healers. Associating contraception's, abortions and other natural forms of healing and problem solving with witches allowed for the prosecution of women and their knowledge. Federici also introduces Margaret Murry's argument that "witchcraft was an ancient matrifocal religion to which the Inquisition turned its attention after the defeat of heresy." (Federici, 2004 p. 180) The older women of the communities who "embodied the communities' knowledge and memory" were also most likely to "resist the destruction of communal relations caused by the spread of capitalist relations", making them prime targets at home and abroad. For example, "prosecuting women as witches the Spaniards [could target] both the practitioners of the old religion and the instigators of anti-colonial revolt, while attempting to redefine the spheres of activity in which the indigenous women could participate.” (Federici, 2004)

\section{Capitalism}

"My goal in life is to change the entire social and economic structure of western civilization, to make it a feminist world." - Marilyn French

Land privatization and commercial agriculture are some of the basic underlying variables of capitalism. The transition from feudalism to capitalism was made possible by separating the peasant class from their communal use of their land; derailing their sense of community as well as self-sufficiency and autonomic way of life as communal agriculture "protected the peasants from harvest failure, due to the variety of strips to which a family had access; it also allowed for a manageable work-schedule (since each strip required attention at a different time); and it encouraged a democratic way of life, built on self-government and self-reliance" (Federici 2004 page 70) Without separating the masses, not only from their land but from each other, without creating an element of deep distrust and distortion of importance, value and abilities feudalism would have not been able to forcibly transform into capitalism. Marx theory of primitive accumulation neglects the role that the witch hunts played in diminishing the women's power in Europe and the Americas in efforts to transform the body into a work-machine and subjugate women as the reproduction of the work-force. (Federici, 2004)

Capitalism essentially restricts one's ability to live self-sufficiently while appropriating the means to do so. Just to highlight one example in the frame of the European witch-hunt that current societies still are struggling with is the development of 'modern medicine'. Women were prosecuted globally for the knowledge and ability of being able to use herbs amongst other natural remedies to heal- i.e. witch craft. Women were stripped of their position of healers and mid wives and their skills appropriated into male dominated upper class occupations with the birth of modern medicine. Not only did this destroy the knowledge passed down of the traditional skill set, creating a dependence on commercial medicine in a male, upper class dominated arena, especially critical to 'women health issues', but this switch also impeded the availability and access of such care. This extraction of knowledge was not limited to just the witches, but all shamans and peoples of traditional culture that were prosecuted for practicing their way of living. Today the pharmaceutical industry profits off populations wellness 
or lack thereof, while holistic measures aren't being properly addressed. "Capitalism has created more brutal and insidious forms of enslavement, as it has planted into the body of the proletariat deep divisions that have served to intensify and conceal exploitation. It is in great part because of these imposed divisions- especially those between women and men- that capitalist accumulation continues to devastate life in every corner of the planet" (Federici, 2004 p. 64)

\section{Environment}

"The pressure of occupation and the incessant stream of impressions pouring into our consciousness thru all the gateways of knowledge make modern existence hazardous in many ways" ... "Every effort under compulsion demands a sacrifice of life-energy" (Tesla, 2017 page 1, 11)

Traditional partnership cultures' respect and closeness to nature with its powers cultivated predominately by women being destroyed and exploited to fit the modern domineering systems at play should leave no room for shock when we look at our planets current environmental state. The destruction of the spiritual world and the traditional ties to, leave the natural world exposed to the same dangers of destruction and exploitation. There is a direct correlation between gender equality and helping our environment. Even by remaining in the same basic constraints of the current dominating system but restoring some elements of feminine power in the focus of equaling girls and women's access to resources including education, we can ease the burden placed upon our planet. In 2017 the United Nations Educational, Scientific and Cultural Organization (UNESCO) estimated that 130 million girls were still restricted from receiving an education. Educated girls and women are more likely to use condoms for disease control as well as birth control, cutting down the spread of diseases as well as global population numbers. Educated girls and women are also more likely to hold agency in their household and society. Placing girls and women in decision making positions for their lives, allocation of resources, and innovations of technology and advancements needed. According to the figures put out by Drawdown, an agency targeted to promoting existing technologies and immediate changes to ease global warming, women make up $43 \%$ of small share farmers and yet generate $60 \%$ - $80 \%$ of food production in developing countries. Even though production numbers are high, women still do not receive the same access to resources. Being as efficient farmers as men but less equipped to do their jobs, their small farms yield roughly 20-30\% less than their potential. By equally allocating resources to small crop farmers, we can feed 100-150 million more people from the same plots of land while curbing the need to clear more forests for farm land and lessening greenhouse emissions. (Drawdown, 2016 )

Taking steps back is not how we move forward; however, we can slow down, learn from our missteps and redirect our steps going forward. Imagine a partnership economy not based on profit but surviving on mutual well-being. Imagine a world without any borders. Imagine everyone having access to our now modern basic needs- clean water, food, shelter, autonomy, electricity and internet. Imagine a garden at every corner instead of a fast food restaurant. Imagine human powered travel, easing our carbon footprint, slowing down the pace of the modern global beat and making travel accessible to all the people of the world.

This is not only a necessary but achievable goal. Redirecting the focus of the global markets from a competitive to cooperative measure can begin to truly alleviate our world's disorder. For example, currently there is a race between China and America for 5G technologies. These technologies have the potential to change how quickly one can download movies to the core functionalities of major cities. As the worlds 'power house' countries engage in modern war over technologies, their people still suffer the consequences for their governments unspoken wars with each other. In these modern war times tactics such as tariffs are used for battle. As seen by Donald Trump who, in effort to punish or slow down Chinas technological advances, has placed tariffs on Chinese goods that will predominately hurt American companies and consumers when they are left to pay the tab. Meanwhile as power hungry countries fight for technological control and conveniences, a large portion of the world still does not have access to such privileges. According to the internet world stats, just over 4 of the 7 
billion people in the world access the internet (Internet World Stats), and roughly 1.3 billion of the world's population still does not even have access to electricity. (Lindeman, 2015) Yet rulers are still causing unnecessary suffering to their people for powers sake. Focusing our technological innovations on a more inclusive and environmentally friendly goal is one way to promote global harmony. Imagine the potential harmony and functionality of the world if we were all working for each other instead of against each other for profit and power.

When we dissect the global refugee crisis it is apparent either direct or indirect imperialist meddling has caused conflict to disperse such large numbers of populations. Then in return said populations are shunned and demonized by the very same governments and systems that have caused the issue. This influx of forced migration puts a strain on the environment and resources in which refuge is sought. For example, Lebanon is the largest refugee host per capita in the world. Over thirty percent of their population consist of refugees, more specifically 1.5 million Syrians and about 250,000 Palestinians. (World Impact News) Both populations of displaced peoples have stemmed from American involvement and other similar capitalistic pursuits to gain resources and power in the guise of "international aide". When looking at Americas 'Border Crisis', although the numbers vary amongst sources, a substantial number of confiscated guns in Mexico and Central America can be traced back to the United States. Where domestic terrorism is on the rise and organizations like the NRA are fighting to protect the selling and owning of guns. This profit over reason pattern is mirrored in Americas billion dollar industry of selling weapons of mass destruction to leaders around the world, including the Saudi Arabian prince who in turn uses such weapons in Syria. This cyclical tornado of destruction and profit touches everyone globally in some form or fashion. Bullets and bombs have no names on them, killing man woman and child equally, causing conflict that forces men and some women to fight in battle, leaving families broken and women and children vulnerable to harsh and devastating shockwaves left by such atrocities.

"You cannot judge the real nature of a European revolutionary doctrine on the basis of the changes it proposes to make within the European power structure and society. You can only judge it by the effects it will have on non-European peoples." - Russell Means (Means, 1980)

As good hearted, spiritual intellectuals gather to share like-minded ideas in efforts to create a better way for the world, how far will we get "using the oppressors' tools" for means of our revolution? The traditional peoples of lands across the world have and continue to be attacked, exploited and erased. Oral histories lost in the mouths of those murdered in the name of religion, economic growth and/or democracy, and yet we think paying tuition to an institution for a piece of paper will open doors for change. We consume thoughtlessly for the sake of convenience, our buried self-loathing or because we have been stripped of our intuition, our self-sufficient abilities, our partnership framework and reprogramed to something so unnatural and destructive. Many of us do not know where our food comes from, spend most of our days breathing in fake air, sitting under fake light and we are considered the 'lucky ones'. We continue to look for quick fixes to (or advances in) our artificial life without a truly deeper holistic approach. By better understanding where our environmental and communal ties were destroyed, in strong part to the demise of feminine power, we can individually begin the work on ourselves and with each other to break through the current oppressive systems and step towards a new system of global harmony. 


\section{References}

Bakara, Ajuma (2017, Aug 17). The Story of Charlottesville was written in Blood in the Ukraine. https://www.counterpunch.org/2017/08/17/the-story-of-charlottesville-was-written-in-blood-in-the-ukraine/

Berlatsky, Noah (2013,Sept5).What Makes America so Prone to Intervention. https://www.theatlantic.com/national/archive/2013/09/what-makes-america-so-prone-to-intervention/279393/

Federici, Silvia, 2004, Caliban and the Witch 1st edn. (Brooklyn, NY : Autonomedia)

Feminism. (n.d.). In Merriam-Webster's online dictionary (11th ed.). Retrieved from https://www.merriamwebster.com/dictionary/femininism

Global Impact News (15 April 2019). “Global NGO Impact News”.

https://globalimpactnews.com/2019/04/15/humanitarian-responses-to-population-displacement-must-also-

protect-the-environment/hooks, b. (2014). Understanding Patriarchy. Imagine Borders, 1-4 https://imaginenoborders.org/pdf/zines/UnderstandingPatriarchy.pdf

Internet World Stats. (2019, May 20). Internet World Stats. Retrieved from https://internetworldstats.com/stats.htm

Lindeman, Todd (10 November 2015). "1.3 Billion are Living in the Dark".

https://www.washingtonpost.com/graphics/world/world-without-power/?noredirect=on

Masculinity and Femininity: Various discourses on gender in India. Shodhganga $\quad$ (2015, Dec 4) CH 3 154181, DOI:10.6031/14300/13/13

Means, Russell (1980, July). For America to live, Europe must die.

http://www.blackhawkproductions.com/russelmeans.html

Roberts, Dorothy E., "Racism and Patriarchy in the Meaning of Motherhood" (1993) Faculty Scholarship Paper 595 https://scholarship.law.upenn.edu/faculty_scholarship/595

Sahely, B (2017, Aug 26) Is Euro centrism (white supremacy) the Root Problem of our Present World Disorder. https://bsahely.com/2017/08/26/is-eurocentrism-white-supremacy-the-root-problem-of-our-present-world-

disorder/

Stokely, Carmichael (29 October 1966). "Black Power".

http://voicesofdemocracy.umd.edu/carmichael-black-power-speech-text/

Tesla, Nikola, 2017, My Inventions and Other Writings Dover Thrift edn. (Mineola, NY: Dover Publications)

White Supremacy. (n.d.). In Merriam-Webster's online dictionary (11th ed.). Retrieved from https://www.merriam-webster.com/dictionary/white\%20supremacy

Women and Girls Small Share Crop |Farmers. (2017) https://www.drawdown.org/solutions/women-andgirls/women-smallholders

World Bank. (2017, September 27).Girls Education Over View. Retrieved from https://www.worldbank.org/en/topic/girlseducation 